\title{
Capacity and predictors to perform integrated leading, managing and governing practices for results among the health system workforce: cross- sectional survey
}

\section{Yeshambel Agumas Ambelie ( $\square$ tgyesh@gmail.com )}

Department of Health Service Management and Health Economics, School of Public Health, Bahir Dar University

\section{Getu Degu Alene}

Department of Biostatistics and Epidemiology, School of Public Health, Bahir Dar University

\section{Damen Hailemariam Gebrekiros}

Department of Health Service Management and Health Economics, School of Public Health, Addis Ababa University

\section{Research article}

Keywords: Health system, Performance, Capacity, Leading, Managing, and Governing, Practices, Factor analysis, Ordinal logistic regression

Posted Date: November 2nd, 2019

DOI: https://doi.org/10.21203/rs.2.10541/v3

License: (c) (i) This work is licensed under a Creative Commons Attribution 4.0 International License. Read Full License 


\section{Abstract}

Introduction: Observing over-led and under-managed, over-managed and under-governed, and even out of these health organizations remains a common phenomenon in low and middle-income countries.

Objective: To determine the capacity and predictors to perform integrated leading, managing and governing practices for results among the health system workforce.

Methods: A cross-sectional study, from December to January 2018, was carried out in northwest Ethiopia. Eight hundred thirteen health facility employees were selected to rate her/his respective staff's capacity on performing integrated leading, managing and governing practices for results. The capacity with $95 \%$ $\mathrm{Cl}$ was computed from 20 items loaded in a four-factor measurement model and leveled into four ordinal categories. Moreover, predictors of this capacity were identified by conducting ordinal logistic regression analysis.

Results: From 813 participants, 396 (48.7\%) and 582 (71.6\%) were females and service owners respectively. The magnitude estimates for the low, moderate, high and very high capacity levels with $95 \%$ Cl were 41.3\% $(37.8,44.6) ; 42.7 \%(39.5,46.0) ; 13.5 \%(11.2,15.9)$ and $2.5 \%(1.5,3.7)$, respectively. Sex $(p=$ $.031)$ and responsibility $(p=.019)$ were identified as the main predictors.

Conclusions: The capacity to perform integrated leading, managing and governing practices for results among the health system workforce in northwest Ethiopia is inadequate. Sex and responsibility are identified as the main statistically significant predictors. The policymakers, program planners and researchers need to take action giving due attention to females and service owners. Feature research could be conducted considering hierarchical variables, mixed design, and large sample size.

\section{Introduction}

Observing over-led and under-managed, over-managed and under-governed and even out of these health organizations remains a common phenomenon, particularly, in low and middle-income countries(1). This puzzle has been palpated in dealing with the successes, glitches, and trends of health initiatives to ensure Universal Health Coverage (UHC). Particularly, in driving the Millennium Development Goals (MDGs) that were in place from 2000 to 2015, diverse experiences were recorded from countries around the globe(2). Reports show that many countries have made incredible achievements; some others made optimal improvements and few with little progress. These trends doubted the reachability of the goals at a considerable number of countries. This doubt unduly pressured the globe to sit for a strategy (3-5). Consequently, leadership and governance is identified as the backbone of the health system $(6,7)$. This is also underlined to be continuing as a locus in executing Sustainable Development Goals (SDGs)(8).

Currently, there is a promising signal in that the health system workforce at all levels look forward to applying a scientifically reliable and empirically scalable integrated leading, managing and governing practices for results $(9-11)$. The signal is skyrocketing among the health system workforce in low and 
middle-income countries who are assigned to ensure UHC in an increasingly socially, politically, economically and technologically turbulent ecosystem(2).

Although integrated leading, managing and governing practices for results has caught the attention of the health system workforce in the low and middle-income countries, yet, there has been a dearth of attempts to develop or test scientifically reliable and empirically scalable practices among the three paths(11-14). Four major reasons can be mentioned to such limited attempts. First, since long ago, concepts of leadership $(15,16)$, management $(17,18)$ and governance $(19,20)$ have been seen as separate agencies. Second, preaching these paths as they belong to an elite group of people who are naturally gifted, rather than discoursing as every ones job. Third, poor integration between the three worlds: civil service, academic sphere and research institute. Usually, the workforce residing in civil service focuses on how to do it; those nesting in the academic sphere emphasize what it is; and those living within research institute stress on how to model it. Lastly, the concept of integrated practices of the three paths for results is mainly donor-driven, not initiated from within the countries.

Some studies indicate that the health system workforce who are competent in performing leading, managing, and governing practices for results improve the health service outcomes(1, 10, 21-24). Some other studies report that there is a significant duplication among the practices of the three dimensions(22, 23). Yet, as the best of our knowledge, no study determined the capacity of the workforce to perform the integrated leading, managing and governing practices for results and identified its predictors. This needs rethinking and redesigning beyond the rhetoric(25-27).

Therefore, the current study aimed at determining the capacity and predictors to perform integrated leading, managing and governing practices for results among the health system workforce. This was carried out after developing a scientifically reliable and empirically scalable measurement model benchmarking the Management Science for Health (MSH) integrated health system leading, managing and governing practices for results framework $(9,14)$, illustrated in figure 1.

Figure 1. Integrated health system leading, managing and governing practices for results model (Source: $\mathrm{MSH}, 2015)$

This model has been introduced in many low and middle-income countries including Ethiopia(14). It consists of twelve practices, of which four-practices are put parallel for leading, managing, and governing in equidistant $(25,28,29)$. Nonetheless, neither how these practices are correlated nor modeled is yet reported.

\section{Methods}

\section{Study design and participants}

A cross-sectional study was carried out from December to January 2018. Thirty-two health care facilities located in northwest Ethiopia were participated. Eight hundred thirteen health facility employees were 
selected, using simple random sampling technique, from the 32 health facilities. The employees worked in the health facilities that deployed staff for integrated leadership, management, and governance inservice training so far were excluded.

\section{Data collection and analysis}

Data were collected using a pretested structured self-rated multi-item questionnaire. It was comprised of the participants' socio-demographic characteristics (sex, age, educational level, responsibility, and year of service) and items measured the Dependent Variable (DV) that is the capacity to perform integrated leading, managing, and governing practices for results. Each participant rated his/her respective staff's capacity using 26 items (Table 2). The 26 items were a five-point Likert scale, ranging from $1=$ very low to $5=$ very high. From these, ten items were on leading practices, eight items were on managing practices and the remaining eight were on governing practices. The test stimuli (psychometric properties) of the questionnaire was refined through rigorous debriefing sessions. The debriefing was focused on questionnaire clarity and validity. Five specialists of health service management, of whom three were from civil service and two from the academic spheres were involved. The questionnaire was pretested on 42 participants working in similar settings but out of the actual study setting. Finally, an item was retained only if there was an internal consistency, alpha value of $80 \%$ or greater(30).

Data were analyzed using Statistical Package for Social Science (SPSS). Data analysis techniques such as descriptive, exploratory factor, composite reliability, average variance extraction, and ordinal logistic regression were conducted. Descriptive statistics was employed to summarize the information about the socio-demographic characteristics of the participants (Table 1) and the central tendency of the rated items (Table 2). Exploratory Factor Analysis (EFA) was unlocked to develop a measurement model through assembling latent factors extracted, items loaded and error variances observed. Here, four data to model fit indices were tested. Firstly, inter-correlation of.3 and greater was checked between items. Secondly, Kaiser-Meyer-Olkin (KMO) test of overall Measure of Sampling Adequacy (MSA) of.5 and greater with Bartlett's test of sphericity $(\mathrm{p}<.05)$ and intra-item consistency of.7 and greater were verified. Thirdly, the total variance explained by $60 \%$ and greater was proved. Lastly, communality of. 5 and greater was confirmed. The communality represented a proportion of each item's variance that can be explained by the factors $(31,32)$. Two items, looking for best practices and match deeds to words (Table 2), were removed from the original dataset due to violating the rule of communality. This reduced the dataset to a 24-item. EFA was iterated to extract factors and to display factor loadings using principal axis factoring method with varimax rotation and a cut point of eigenvalue greater than 1 . But, additional four items: set annual and strategic plan, allocate adequate resources, provide accountability and authority and provide appropriate feedback (Table 2) were removed from the 24-item dataset due to violating the rule of complex structure that is any factor had not resided on more than one item with factor loadings of. 4 and greater(33). It showed that the dataset that satisfied the requirements of factor analysis was reduced again to a 20-item. From this dataset, the measurement model (Figure 2) that used to determine the DV was developed. As noted earlier, this was carried out by assembling factors extracted, items loaded and 
error variances observed. An item was a measured variable that is clustered within a latent factor; a latent factor was unobserved variable which typically could not be directly measured, but it was assumed to cause the observed scores on the item, and error variance was the portion of the factor that could not be predicted from the remaining factors.

\section{Figure 2: Measurement model: integrated leading, managing, and governing practices for results}

The above figure indicates the four-factor measurement model. Observing the figure from left to right, the lines rayed from the integrated leading, managing, and governing practices for results denote the latent factors extracted. The lines radiated from each factor towards the item represent the degree of correlation of each item with the corresponding factor. The lines reflected against each item symbolize the error variance. These variances were calculated from one minus communality, which explained the portion of each observed item that was not predicted from the factors. The higher error variance ( .5 and greater) indicated that an item might not belong to any factor. The four latent factors extracted were labeled considering the contents (scientific and empirical domains) of the items clustered within each factor(31, $34,35)$. The eight items that loaded highly on factor 1 seemed to value the different aspects of organizational principles. Thus, this factor was labeled as compliance with principles. Besides, the four items that loaded highly on factor 2 contained diverse characteristics of strategy. Hence, it was termed as strategic sensitivity. Additionally, another four items that loaded highly on factor 3 appeared to correlate to various features of system development. Then, it was named as system building. Finally, the remaining four items that loaded highly on factor 4 gave the impression to relate to context, which accordingly was called contextual thoughtfulness.

Moreover, the reliability and validity of the measurement model were tested $(36,37)$. The reliability of the model was tested with Composite Reliability (CR), which was calculated from the squared sum of factor loadings divided by the squared sum of factor loadings and the sum of error variances(38). To reaffirm the reliability of the model the $\mathrm{CR}$ was triangulated with the total variance explained. Whereas, the validity of the model was tested using the Average Variance Extraction (AVE), which was triangulated with factor correlations. AVE was calculated from the sum of factor loading squared divided by sum of factor loading squared and sum of error variances(39). The square root of AVE was also considered, by which the presence of validity was supported if this value was greater than most of the correlation coefficients of items clustered within its factors. Correlations were also tested whether they were significantly different from zero, which supported convergent validity; or the higher number of times that the item highly correlated within its factor compared with the items of the other factors, that covered the divergent validity. Here, the percent of variability that the items shared was determined by squaring the correlations between items and multiplied by 100 . Generally, the rule is that items should relate more strongly to their factor than to another factor. 
Here, the authors want to note that the detailed outputs of the correlations of items; internal consistencies and communalities of original items; total variance explained; factor loadings and communalities of items only loaded and CR and AVE of the factors indicated on the four-factor measurement model were enclosed in the supplementary file. These were represented with S1, S2, S3, S4, and S5, respectively.

Following the above analyses, the DV was computed from the 20 items indicated on the measurement model. This again was leveled into four ordinal categories: low, moderate, high and very high that represented scores of $<60,60-79.99,80-94.99$ and $>95$, respectively. This was done based on categories indicated in the performance appraisal guideline of the Ethiopian ministry of health.

Next, ordinal logistic regression analysis with logit link function was conducted to model the relationship between the DV and its predictors. Model fitting information tested by (-2Log Likelihood) was significant at $p<.001$. Besides, the consistency of the observed data tested with Pearson chi-square goodness-of-fit was remained satisfactory with $p=1$. Besides, the explained variance of $D V$ from the predictors was tested by pseudo-r-squared value (Nagelkerke's $\mathrm{R}^{2}=.765$ ), which indicated a strong association.

Moreover, the test of parallel lines or testing proportional odds assumption that is testing whether the location parameters (slope coefficients) of predictors were the same across outcome variable categories was tested by ( -2 Log Likelihood) and became non-significant with $p=.487$. This showed that the slope coefficients were the same across response categories, which told that there had no evidence to reject the parallelism hypothesis. Finally, to interpret the impact of individual predictors in a better way, odds ratios with $95 \% \mathrm{Cl}$ were calculated from the odds.

\section{ETHICAL APPROVAL}

Ethical clearance with a protocol record 090/18-04 was secured from the institutional review board of Bahir Dar University. Each participant provided written consent.

\section{Results}

\section{Socio-demographic characteristics of participants}

Table 1 presents the participants' socio-demographic characteristics. From 813 participants, 396(48.7\%) were females and 582 (71.6\%) were service owners.

\section{Central tendency of the measuring items}

Table 2 indicates the means and standard deviations of measuring items that summarized their central tendencies. 


\section{Capacity to perform integrated leading, managing, and governing practices for results}

Figure 3 indicates the capacity to perform integrated leading, managing, and governing practices for results among the health system workforce. The $95 \%$ confidence interval for low, moderate, high and very high levels were $(37.8,44.6) ;(39.5,46.0) ;(11.2,15.9)$; and $(1.5,3.7)$, correspondingly.

\section{Predictors that affect capacity to perform integrated leading, managing, and governing practices for results}

Table 3 displays the estimated coefficients of the ordinal logistic regression model. The estimates labeled "threshold" indicated that where the latent variable was cut to make the groups that were observed in the table, other ways it was not used in the interpretation of the results.

The other estimates labeled "location" were the ones that the researchers interested in, which were the coefficients (odds) of the predictors. To interpret the impact of individual predictors in a better way, proportional odds ratio with $95 \% \mathrm{Cl}$ was calculated by coefficient exponentiation, which were indicated in the exponential (EXP) column of the table. From the observed significance levels: sex and responsibility were significantly related $(p<.05)$. Whereas, age, educational level and service year were appeared nonsignificant ( $p>05)$. For example, the odds ratio of male health system workforce was $1.502(95 \% \mathrm{Cl}$, 1.038 to 2.173 ). This could be interpreted as being male health system workforce was $50.2 \%$ higher to perform integrated leading, managing, and governing practices for results in a very high level compared with those of females $(p=.031)$.

Furthermore, all the six items that trimmed from the measurement model due to violating the requirements of factor analysis and treated as predictors were significantly related to the capacity of the workforce $(\mathrm{p}<.05)$. For instance, the odds ratio of the workforce who had a very low rate of 'looking for best practices' was.029 (95\% $\mathrm{Cl}, 011$ to.080). This inferred that a very low rate of 'looking for best practices' reduced the workforce's level of capacity by $97.1 \%$ compared with a very high rate $(p=.000)$.

\section{Discussion}

The low and moderate levels of capacity to perform integrated leading, managing and governing practices for results accounted for $84 \%$ among the health system workforce in northwest Ethiopia. Sex and responsibility are identified as the main statistically significant predictors. The other statistically significant predictors are looking for best practices, match deeds to words, set annual and strategic plan, allocate adequate resources, provide accountability and authority, and provide appropriate feedback.

Regarding sex, being a male workforce has a higher capacity to perform integrated leading, managing, and governing practices for results. This deviation might arise from that the limited number of females are authorized to lead, manage, and govern organizations. In Ethiopia, this has a historical trend, in which 
breaking it and bringing the adequate number of females to the stage is a troublesome investment. However, almost $50 \%$ of the participants in this study are females, which might indicate that a considerable number of the workforce in the health system are females. Thus, whatever reasons people have, without empowering half of the segment of the workforce, getting organizations to the intended stage would be rather impossible. Concerning responsibility, being head of the office has more than twofold higher capacity compared with the service owner. The potential reason might be that the service owners take limited training in the field. This together with the existed rhetoric (noted in the introduction section) make the service owners incapable of it. This directs that huge investment in integrated leading, managing, and governing practices for results is awaiting service owners, almost $3 / 4^{\text {th }}$ of the workforce. About the other six significant predictors, as explained in the methods section, essentially these were developed among items to measure the DV, but later on, due to violating the requirements of factor analysis they are taken as predictors(33). However, their higher significant relationship with the capacity implies that in scheming integrated leading, managing, and governing practices for results projects; considering them as measuring items would be more meaningful. Accordingly, looking for best practices can be captured by contextual thoughtfulness; match deeds to words can be enclosed within strategic sensitivity; items like set annual and strategic plan, allocate adequate resources and provide accountability and authority can be nested within system building; and provide appropriate feedback can be contained by compliance with principles (figure 2).

As noted earlier, yet, no study reports the capacity of the health system workforce to perform integrated leading, managing, and governing practices for results and its predictors. Rather, some studies simply show that the health system workforce who are competent in performing leading, managing, and governing practices improve the health service outcomes $(1,10,21-24)$. Also, some other studies reported that there is a significant duplication among the practices of the three dimensions $(22,23)$. These study reports say nothing about the depth of such duplications while there are works of literature that encourage discussing. Regarding to leadership: level of organizing details, the stand of the people to do what they would ask another to do, expectation of what people paid for, perception towards colleagues, level of creativity, self-perception, indulgence, level of loyalty, leadership approach, title and expertise, environment, and common sense are reported as determinants of it(40). Likewise, division of work, authority, and responsibility, discipline, unity of command, unity of direction, subordination of individual interest, remuneration, the degree of centralization, scalar chain, order, equity, stability of tenure of personnel, initiative and esprit de corps are indicated as elements of management(17). Similarly, leadership, corruption, management, transparency, accountability, systems to manage data, participation of key stakeholders, political context, check and balance strategy, and financial resources are specified as basis of governance(19). These exemplifications clearly show that one path is even accounted as determinant for the other path. For instance, leadership and management are mentioned as determinants of governance. Additionally, regardless of the level of specificity, most-perhaps-all of the characteristics mentioned as determinants in one path have a twin concept in the other paths. For example, common sense, unity of direction, and participation of stakeholders are similar concepts but mentioned as determinants of different paths. Moreover, the determinants exemplified above might be less helpful, 
particularly, when policymakers, programmers, planners and researchers designing projects on integrated leading, managing, and governing practices for results based on socio-demographic characteristics such as sex and responsibility.

Generally, the current study tried to fill the existed gaps by determining the capacity of the health system workforce integrated leading, managing, and governing practices for results and identifying its predictors using a scientifically reliable and empirically scalable four-factor measurement model that amalgamated latent factors extracted, items rated and error variances observed. Such practices improve health results by balancing the people's needs, workloads and organizational requirements.

Away from all the implications, the results of the current study ought to be interpreted with two-fold limitations. First, as the questionnaire was self-rated, there might have been some information bias. Second, results from such a small sample size to the entire health system workforce could be generalized with caution.

\section{Conclusions}

The capacity to perform integrated leading, managing and governing practices for results among the health system workforce in northwest Ethiopia is inadequate. Sex and responsibility are identified as the main statistically significant predictors. The policymakers, program planners and researchers need to take action giving due attention to females and service owners. This can be also considered in similar settings. Feature research could be conducted considering hierarchical variables, mixed design, and large sample size. In future actions, noting the current four-factor measurement model might be helpful.

\section{Abbreviations}




\begin{tabular}{|c|c|}
\hline AVE & Average Variance Extraction \\
\hline BDU & Bahir Dar University \\
\hline BSC & Balance Score Card \\
\hline $\mathrm{Cl}$ & Confidence Intervals \\
\hline CR & Composite Reliability \\
\hline EFA & Exploratory Factor Analysis \\
\hline Epi-Info & Epi-demographic Information \\
\hline EXP & Exponential \\
\hline $\mathrm{FMoH}$ & Federal Ministry of Health \\
\hline KPIs & Key Performance Indicators \\
\hline KMO & Kaiser-Meyer-Olkin \\
\hline$L+M+G$ & Leading, Managing and Governing \\
\hline MDGs & Millennium Development Goals \\
\hline MSA & Measure of Sampling Adequacy \\
\hline MSH & Management Science for Health \\
\hline OR & Odds Ratio \\
\hline ORLA & Ordinal Logistic Regression Analysis \\
\hline SDG-3 & Sustainable Development Goal-3 \\
\hline SPSS & Statistical Package for Social Science \\
\hline$P$ & Probability value \\
\hline PhD & Doctor of Philosophy \\
\hline UHC & Universal Health Coverage \\
\hline WHO & World Health Organization \\
\hline
\end{tabular}

\section{Declarations}

\section{DATA AVAILABILITY}

The dataset supporting the current conclusions is included in the article and supporting file.

\section{AUTHOR CONTRIBUTIONS}


YA pictured the original idea, designed the study and participated in all performance stages of the project; analyzed the data and finalized to write the manuscript.

GA pictured the original idea, designed the study and participated in all performance stages of the project; analyzed the data and finalized to write the manuscript.

DG pictured the original idea, designed the study and participated in all performance stages of the project; analyzed the data and finalized to write the manuscript.

All authors reviewed and approved the final manuscript.

\section{COMPETING INTERESTS}

All the authors declare that they have no competing interests.

\section{FUNDING STATEMENT}

This work was supported by Bahir Dar University $[056,2018]$.

\section{ACKNOWLEDGMENTS}

Our special thanks and sincere appreciation go to the study participants, data collectors, and data supervisors, for their respective valuable contribution. Our gratitude also extends to Bahir Dar University for funding this study, which is part of a Ph.D. dissertation research.

\section{References}

1.Fetene N, Canavan ME, Megentta A, Linnander E, Tan AX, Nadew K, et al. District-level health management and health system performance. PloS one. 2019;14(2):e0210624.

2.World Health Organization. Everybody's business-strengthening health systems to improve health outcomes: WHO's framework for action. 2007.

3.Van Lerberghe W. The world health report 2008: primary health care: now more than ever: World Health Organization; 2008.

4.Frenk J. Reinventing primary health care: the need for systems integration. The Lancet. 2009;374(9684):170-3.

5.World Health Organization. From alma Ata to the year 2000: reflections at the midpoint. 1988. 
6.Vriesendorp S, De La Peza L, Perry C, Seltzer J, ONeil M. Health systems in action: an ehandbook for leaders and managers. 2010.

7.Daire J, Gilson L, Cleary S. Developing leadership and management competencies in low and middleincome country health systems: a review of the literature. Cape Town: Resilient and Responsive Health Systems (RESYST). 2014.

8.World Health Organization. World Health Statistics 2016: Monitoring Health for the SDGs Sustainable Development Goals. World Health Organization, 20169241565268.

9.Galer JB, Vriesendorp S, Ellis A. Managers who lead: a handbook for improving health services. 2005.

10.DeRue DS, Myers CG. Leadership development: A review and agenda for future research. Oxford handbook of leadership and organizations. 2014:832-55.

11.Martineau T, Raven J, Aikins M, Alonso-Garbayo A, Baine S, Huss R, et al. Strengthening health district management competencies in Ghana, Tanzania and Uganda: lessons from using action research to improve health workforce performance. BMJ global health. 2018;3(2):e000619.

12.Benowitz E. Cliffsquickreview Principles of management: Houghton Mifflin Harcourt; 2001.

13.Federal Ministry of Health. Leadership Management \& Governance In-Services Training Manual. 2017.

14.Management Sciences for Health. Rice JA, Shukla, Mahesh, Johnson Lassner, Karen et al. Leaders Who Govern. June 2015. 2015.

15.Adair JE. Action-centred leadership: McGraw-Hill New York; 1973.

16.Bennis W. The leadership advantage. Leader to leader. 1999;12(2):18-23.

17.Fayol H. Principles of management. URL: http://www grandars ru/college/ekonomika-firmy/anri-fayol html (accessed: October 20, 2015).

18.Drucker P. The frontiers of management: Routledge; 2012.

19.Rice JA. Synyhesis paper effective governance for health 2012.

20.Elliott JE. Karl Marx: Founding Father of Workers' Self-Governance? Economic and Industrial Democracy. 1987;8(3):293-321.

21.Prashanth N, Marchal B, Kegels G, Criel B. Evaluation of capacity-building program of district health managers in India: a contextualized theoretical framework. Frontiers in public health. 2014;2:89.

22.Smith PC, Anell A, Busse R, Crivelli L, Healy J, Lindahl AK, et al. Leadership and governance in seven developed health systems. Health policy (Amsterdam, Netherlands). 2012;106(1):37-49. 
23. Uneke CJ, Ezeoha AE, Ndukwe CD, Oyibo PG, Onwe FD. Enhancing leadership and governance competencies to strengthen health systems in Nigeria: Assessment of organizational human resources development. Healthcare Policy. 2012;7(3):73.

24.La Rue KS, Alegre JC, Murei L, Bragar J, Thatte N, Kibunga P, et al. Strengthening management and leadership practices to increase health-service delivery in Kenya: an evidence-based approach. Human resources for health. 2012;10(1):25.

25.Levey S, Vaughn T, Koepke M, Moore D, Lehrman W, Sinha S. Hospital leadership and quality improvement: rhetoric versus reality. Journal of Patient Safety. 2007;3(1):9-15.

26.Mathauer I, Imhoff I. Health worker motivation in Africa: the role of non-financial incentives and human resource management tools. Human resources for health. 2006;4(1):24.

27.Rauscher M, Walkowiak H, Djara MB. Leadership, Management, and Governance Evidence Compendium. 2018.

28.Bass BM, Stogdill RM. Bass \& Stogdill's handbook of leadership: Theory, research, and managerial applications: Simon and Schuster; 1990.

29.Kouzes J, Posner B. An instructor's guide to the leadership challenge. San Francisco: Jossey-Bass; 1995.

30.Avolio BJ, Bass BM, Jung DI. Re-examining the components of transformational and transactional leadership using the Multifactor Leadership. Journal of occupational and organizational psychology. 1999;72(4):441-62.

31.Comrey AL, Lee HB. A first course in factor analysis: Psychology Press; 2013.

32.Beaumont R. An introduction to principal component analysis \& factor analysis using SPSS 19 and R (psych package). Factor Analysis and Principal Component Analysis (PCA). 2012;24(8-9).

33.Starkweather J. Principal Components Analysis vs. Factor Analysis... and Appropriate Alternatives. Available in original form at Benchmarks: http://it unt edu/benchmarks. 2010(2010/07).

34.Lolli S, Di Girolamo P. Principal component analysis approach to evaluate instrument performances in developing a cost-effective reliable instrument network for atmospheric measurements. Journal of Atmospheric and Oceanic Technology. 2015;32(9):1642-9.

35.Field A. Factor analysis using SPSS. Retrieved March. 2005;17:2009.

36.C. Fornell and D. F. Larcker. Evaluating structural equation models with unobservable variables and measurement error. Journal of marketing research. 1981:39-50, 
37.Campbell DT, Fiske DW. Convergent and discriminant validation by the multitrait-multimethod matrix. Psychological bulletin. 1959;56(2):81.

38.Raykov T. Estimation of composite reliability for congeneric measures. Applied Psychological Measurement. 1997;21(2):173-84.

39.Alarcón D, Sánchez JA, De Olavide U, editors. Assessing convergent and discriminant validity in the ADHD-R IV rating scale: User-written commands for Average Variance Extracted (AVE), Composite Reliability (CR), and Heterotrait-Monotrait ratio of correlations (HTMT). Spanish STATA Meeting; 2015.

40.Denny R. Motivate to win: how to motivate yourself and others: Kogan Page Publishers; 2006.

\section{Tables}

Table 1: Socio-demographic characteristics of participants $(n=813)$

\begin{tabular}{|c|c|c|c|}
\hline Variable & Category & Frequency & Percent \\
\hline \multirow[t]{4}{*}{ Sex } & Male & 417 & 51.3 \\
\hline & Female & 396 & 48.7 \\
\hline & $<=24$ years & 124 & 15.3 \\
\hline & $25-29$ years & 334 & 41.1 \\
\hline \multirow{3}{*}{ Age } & 30-34 years & 256 & 31.5 \\
\hline & $>34$ years & 99 & 12.2 \\
\hline & Diploma and less & 363 & 44.6 \\
\hline \multirow[t]{2}{*}{ Educational level } & First degree & 411 & 50.6 \\
\hline & Second degree and above & 39 & 4.8 \\
\hline \multirow{4}{*}{ Responsibility } & Head of office & 61 & 7.5 \\
\hline & Process owner & 35 & 4.3 \\
\hline & Unit coordinator & 135 & 16.6 \\
\hline & Service owners & 582 & 71.6 \\
\hline \multirow{4}{*}{ Year of service } & $<2$ years & 209 & 25.7 \\
\hline & $2-4$ years & 222 & 27.3 \\
\hline & $5-8$ years & 283 & 34.8 \\
\hline & $>8$ years & 99 & 12.2 \\
\hline
\end{tabular}

Table 2: Means and standard deviations of measuring items $(n=813)$ 


\begin{tabular}{|c|c|c|c|}
\hline \multicolumn{2}{|r|}{ Item } & \multicolumn{2}{|c|}{ Mean Standard deviation } \\
\hline 1 & Identify client and stakeholder needs and priorities & 3.35 & 1.103 \\
\hline 2 & Recognize trends, opportunities, and risks & 3.36 & 1.076 \\
\hline 3 & Look for best practices & 3.11 & 1.168 \\
\hline 4 & Articulate the organization's mission, strategy and vision & 3.33 & 1.103 \\
\hline 5 & Determine key priorities for action & 3.38 & 1.097 \\
\hline 6 & Enlist stakeholders to commit resources & 2.86 & 1.197 \\
\hline 7 & Unite mobilized resources to reach organizational vision & 2.97 & 1.214 \\
\hline 8 & Match deeds to words & 3.25 & 1.161 \\
\hline 9 & Show trust and confidence and acknowledge contributions & 3.04 & 1.197 \\
\hline 10 & Model of creativity, innovation and learning & 3.00 & 1.160 \\
\hline 11 & Set annual and strategic plan & 3.32 & 1.165 \\
\hline 12 & Allocate adequate resources & 3.04 & 1.172 \\
\hline 13 & Provide accountability and authority & 3.06 & 1.111 \\
\hline 14 & Considers the organizational lines of authority for delegation & 3.24 & 1.126 \\
\hline 15 & Integrate work structures and work flow & 3.16 & 1.091 \\
\hline 16 & Coordinate practices with other staff's programs & 3.22 & 1.097 \\
\hline 17 & Monitor their achievements against the plan, and take lessons & 3.20 & 1.136 \\
\hline 18 & Provide appropriate feedback & 3.19 & 1.125 \\
\hline 19 & Uphold ethical and moral integrity to serve the public interest & 3.24 & 1.230 \\
\hline 20 & Establish a consultation mechanism to heard public voice & 2.95 & 1.171 \\
\hline 21 & Ensure participation of key stakeholders & 2.86 & 1.160 \\
\hline 22 & Establish alliances for joint action at all levels & 2.96 & 1.162 \\
\hline 23 & Oversee a shared direction to achieve organizational mission & 3.10 & 1.240 \\
\hline 24 & Advocate organizational mission and vision to stakeholders & 2.97 & 1.223 \\
\hline 25 & Use resources in a way that maximizes the public well-being & 3.07 & 1.284 \\
\hline 26 & Describe the outcomes related to the allocated resources & 2.76 & 1.231 \\
\hline
\end{tabular}

Table 3: Parameter estimates of predictors fitted to ordinal logistic regression analysis $(n=813)$ 


\begin{tabular}{|c|c|c|c|c|c|c|c|c|c|}
\hline \multicolumn{3}{|c|}{ Variable } & \multirow[t]{2}{*}{ Estimate } & \multirow[t]{2}{*}{ Sig. } & \multicolumn{2}{|c|}{$95 \% \mathrm{Cl}$} & \multirow[b]{2}{*}{ EXP } & \multicolumn{2}{|c|}{$95 \% \mathrm{Cl}$} \\
\hline & & & & & $\begin{array}{l}\text { Lower } \\
\text { Bound }\end{array}$ & $\begin{array}{l}\text { Upper } \\
\text { Bound }\end{array}$ & & $\begin{array}{l}\text { Lower } \\
\text { bound }\end{array}$ & $\begin{array}{l}\text { Upper } \\
\text { bound }\end{array}$ \\
\hline \multirow[t]{3}{*}{ Threshold } & \multirow[t]{3}{*}{ Level of capacity } & Low & -8.329 & .000 & -9.781 & -6.876 & .000 & .000 & .001 \\
\hline & & Moderate & -3.282 & .000 & -4.579 & -1.984 & .038 & .010 & .138 \\
\hline & & High & .932 & .130 & -.273 & 2.136 & 2.540 & .761 & 8.466 \\
\hline \multirow[t]{40}{*}{ Location } & \multirow[t]{2}{*}{ Sex } & Male & .407 & .031 & .037 & .776 & 1.502 & 1.038 & 2.173 \\
\hline & & Female & 0 & . & . & . & 1 & - & - \\
\hline & \multirow[t]{4}{*}{ Age in years } & $\leq 24$ & .359 & .353 & -.398 & 1.115 & 1.432 & .672 & 3.050 \\
\hline & & $25-29$ & -.391 & .236 & -1.037 & .256 & .676 & .355 & 1.292 \\
\hline & & $30-34$ & -.526 & .110 & -1.171 & .119 & .591 & .310 & 1.126 \\
\hline & & $>34$ & 0 & . & . & . & 1 & - & - \\
\hline & \multirow[t]{3}{*}{ Educational level } & $\begin{array}{l}\text { Diploma \& } \\
\text { below }\end{array}$ & .731 & .103 & -.147 & 1.609 & 2.077 & .863 & 4.998 \\
\hline & & First degree & .625 & .152 & -.230 & 1.479 & 1.868 & .795 & 4.389 \\
\hline & & $\begin{array}{l}\text { Masters \& } \\
\text { above }\end{array}$ & 0 & . & . & . & 1 & - & - \\
\hline & \multirow[t]{4}{*}{ Responsibility } & Head of office & .868 & .019 & .144 & 1.592 & 2.382 & 1.155 & 4.914 \\
\hline & & Process owner & -.022 & .965 & -1.030 & .985 & .978 & .357 & 2.678 \\
\hline & & Unit coordinator & .445 & .083 & -.058 & .948 & 1.560 & .944 & 2.581 \\
\hline & & Service owner & 0 & . & . & . & 1 & - & - \\
\hline & \multirow[t]{4}{*}{ Service in years } & $<2$ & .577 & .114 & -.138 & 1.292 & 1.781 & .871 & 3.640 \\
\hline & & $2-4$ & .548 & .119 & -.142 & 1.238 & 1.730 & .868 & 3.449 \\
\hline & & $5-8$ & .392 & .245 & -.269 & 1.053 & 1.480 & .764 & 2.866 \\
\hline & & $>8$ & 0 & . & . & . & 1 & & \\
\hline & \multirow[t]{5}{*}{ Look for best practices } & Very low & -3.531 & .000 & -4.541 & -2.521 & .029 & .011 & .080 \\
\hline & & Low & -2.579 & .000 & -3.356 & -1.802 & .076 & .035 & .165 \\
\hline & & Moderate & -1.602 & .000 & -2.249 & -.954 & .201 & .106 & .385 \\
\hline & & High & -1.278 & .000 & -1.890 & -.667 & .279 & .151 & .513 \\
\hline & & Very high & 0 & . & . & . & 1 & - & - \\
\hline & \multirow[t]{5}{*}{ Match deeds to words } & Very low & -2.030 & .000 & -2.963 & -1.097 & .131 & .052 & .334 \\
\hline & & Low & -3.551 & .000 & -4.415 & -2.688 & .029 & .012 & .068 \\
\hline & & Moderate & -1.657 & .000 & -2.270 & -1.044 & .191 & .103 & .352 \\
\hline & & High & -.559 & .049 & -1.116 & -.002 & .572 & .328 & .998 \\
\hline & & Very high & 0 & . & . & . & 1 & - & - \\
\hline & \multirow[t]{5}{*}{ Set anual and strategic plan } & Very low & -1.208 & .033 & -2.319 & -.097 & .299 & .098 & .908 \\
\hline & & Low & -1.387 & .001 & -2.179 & -.595 & .250 & .113 & .552 \\
\hline & & Moderate & -1.266 & .000 & -1.891 & -.641 & .282 & .151 & .527 \\
\hline & & High & -.391 & .153 & -.928 & .145 & .676 & .395 & 1.156 \\
\hline & & Very high & 0 & . & . & . & 1 & - & - \\
\hline & \multirow[t]{5}{*}{ Allocate adequate resources } & Very low & -.469 & .365 & -1.485 & .546 & .626 & .227 & 1.726 \\
\hline & & Low & -1.227 & .002 & -2.010 & -.444 & .293 & .134 & .641 \\
\hline & & Moderate & -.584 & .104 & -1.289 & .120 & .558 & .276 & 1.127 \\
\hline & & High & -.919 & .006 & -1.575 & -.262 & .399 & .207 & .770 \\
\hline & & Very high & 0 & . & . & . & 1 & - & - \\
\hline & \multirow{3}{*}{$\begin{array}{l}\text { Provide accountability and } \\
\text { authority }\end{array}$} & Very low & -2.877 & .000 & -4.085 & -1.669 & .056 & .017 & .188 \\
\hline & & Low & -2.415 & .000 & -3.279 & -1.552 & .089 & .038 & .212 \\
\hline & & Moderate & -1.791 & .000 & -2.522 & -1.059 & .167 & .080 & .347 \\
\hline
\end{tabular}




\begin{tabular}{llccccccccc} 
& High & -.921 & .007 & -1.591 & -.252 & .398 & .204 & .777 \\
\cline { 2 - 8 } & Very high & 0 &. &. & &. & 1 & - \\
\hline \multirow{2}{*}{ Provide appropriate feedback } & Very low & -4.490 & .000 & -5.947 & -3.033 & .011 & .003 & .048 \\
\cline { 2 - 8 } & Low & -4.069 & .000 & -4.960 & -3.177 & .017 & .007 & .042 \\
& Moderate & -2.383 & .000 & -3.078 & -1.687 & .092 & .046 & .185 \\
\cline { 2 - 8 } & High & -1.381 & .000 & -2.001 & -.761 & .251 & .135 & .467 \\
\hline
\end{tabular}

\section{Figures}

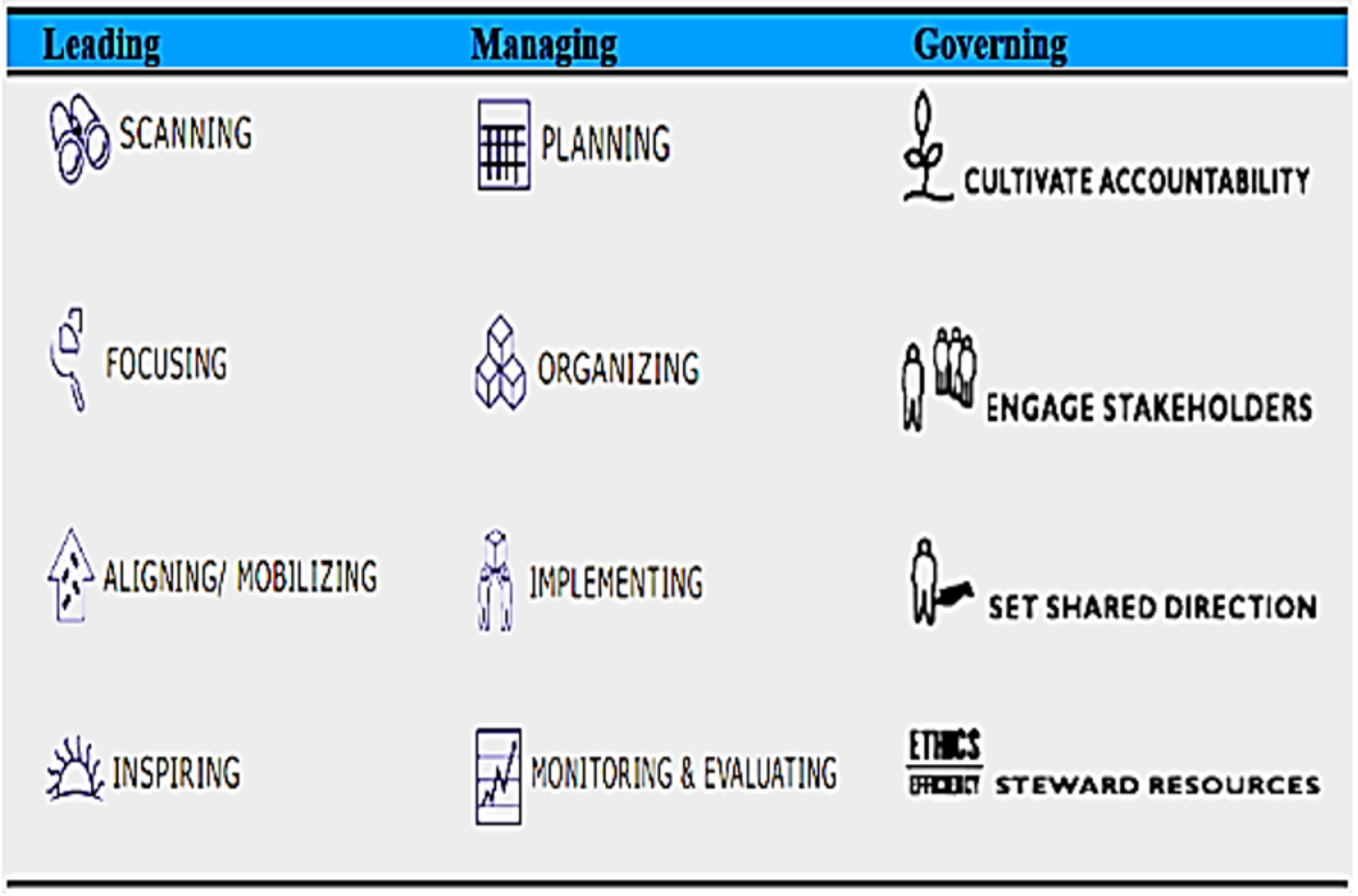

\section{Figure 1}

Figure 1

Integrated health system leading, managing and governing practices for results model (Source: $\mathrm{MSH}$, 2015) 


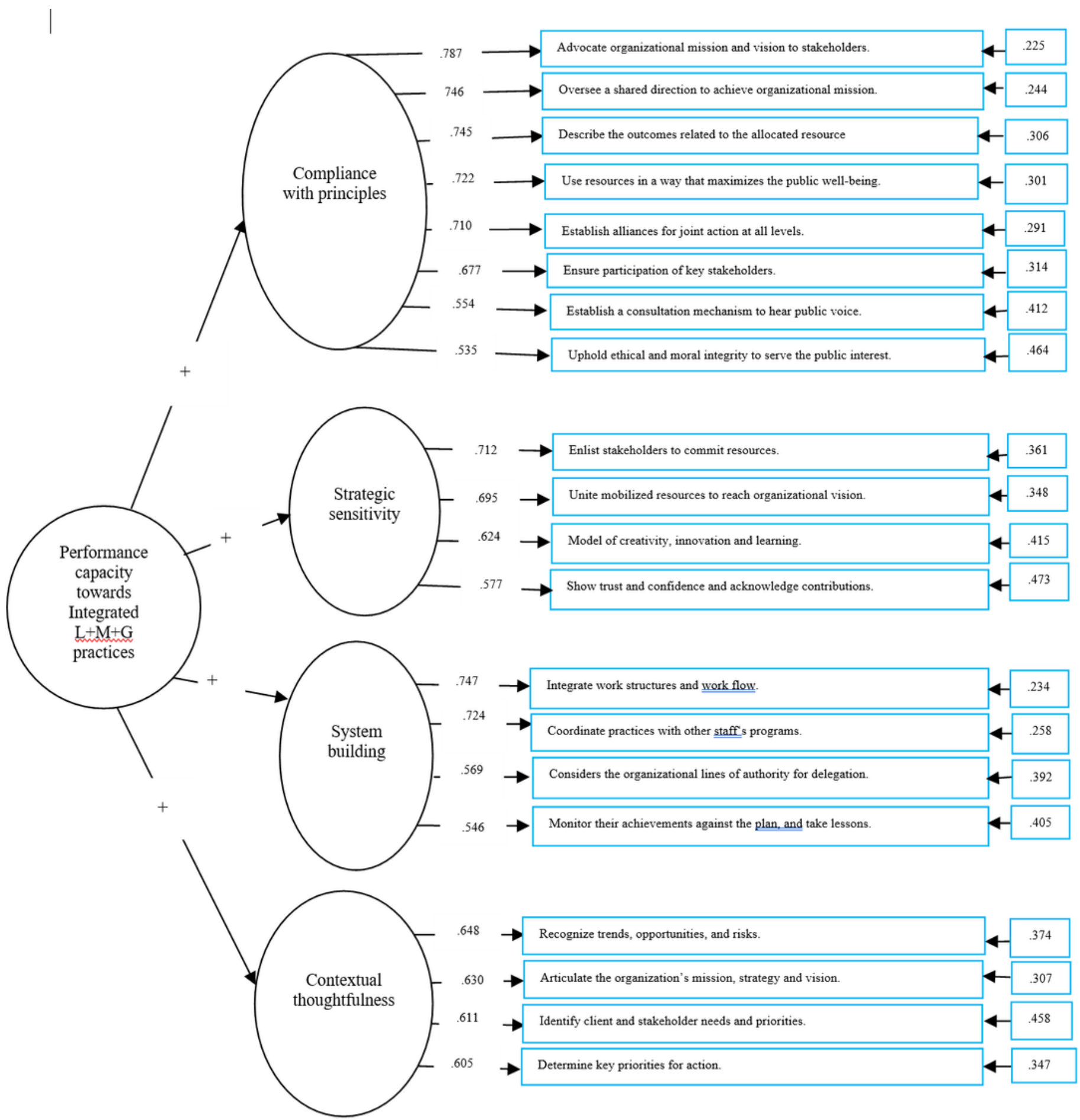

Figure 2

\section{Figure 2}

Measurement model: integrated leading, managing, and governing practices for results 


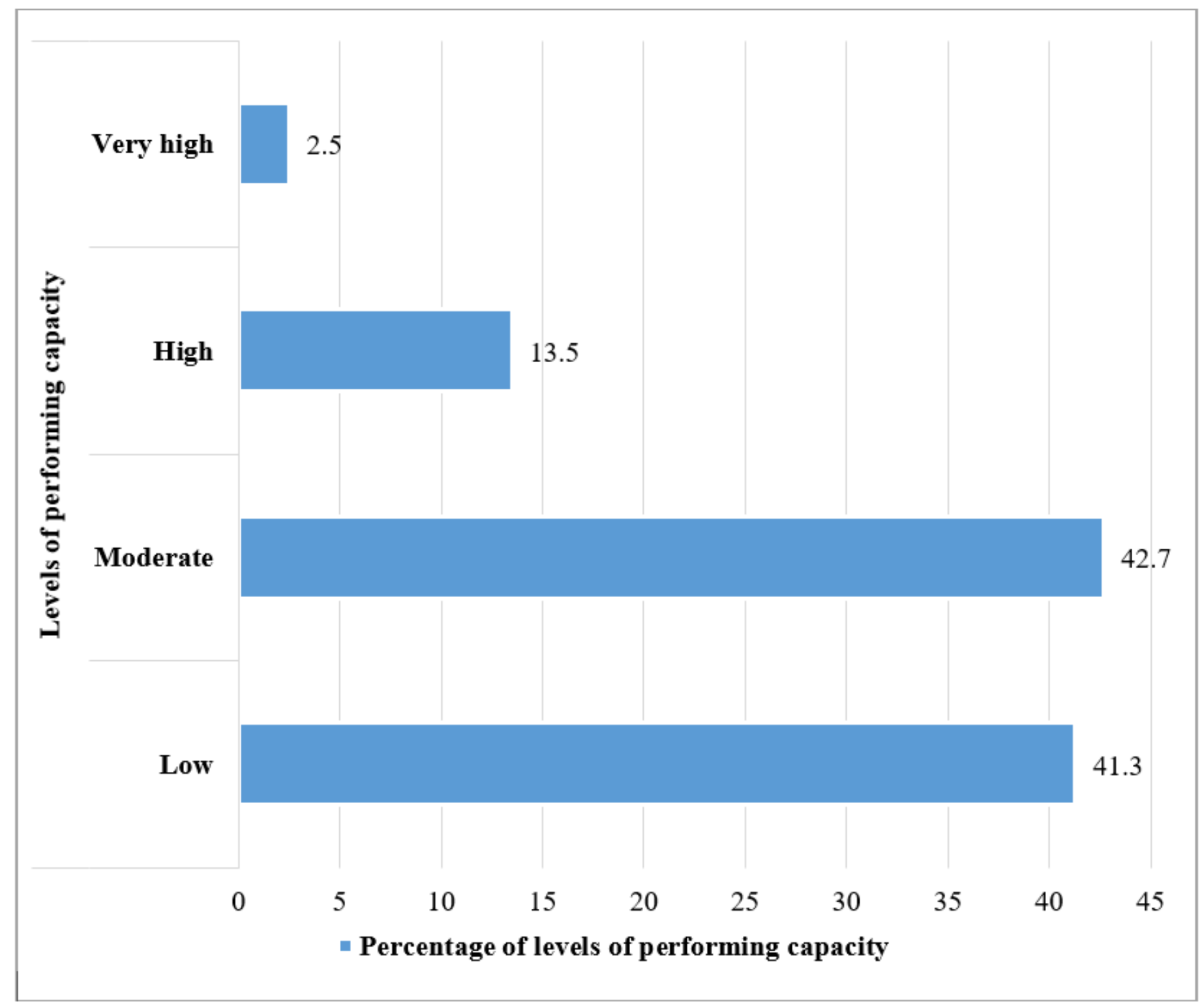

Figure 3

Figure 3

The capacity to perform integrated leading, managing, and governing practices for results among the health system workforce

\section{Supplementary Files}

This is a list of supplementary files associated with this preprint. Click to download.

- Supplementaryfile.pdf 